\title{
CHANGES OF ANTI-GLUCOSIDASE CONTENT AND SOME OTHER CHARACTERISTICS IN MULBERRY JUICE DURING FERMENTATION WITH LEUCONOSTOC MESENTEROIDES
}

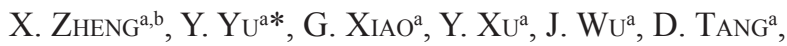 \\ Y. $\mathrm{CHENG}^{\mathrm{a}}$ and Y. ZHANG ${ }^{\mathrm{a}}$ \\ ${ }^{a}$ Sericulture and Agri-food Research Institute, Guangdong Academy of Agricultural Sciences, \\ Guangzhou, 510610. China \\ ${ }^{\mathrm{b}}$ College of Bioscience and Bioengineering, JiangXi Agricultural University, Nanchang, 330045. China
}

(Received: 28 July 2013; accepted: 26 September 2013)

\begin{abstract}
Changes in microbial population, $\mathrm{pH}$, sugar, organic acid, anthocyanins, total soluble phenolics, and anti-glucosidase contents were measured during fermentation of mulberry juice at $30{ }^{\circ} \mathrm{C}$ by probiotic Leuconostoc mesenteroides showing rapid growth after an approximately 1-day lag phase and reaching a maximum of $8.6 \log \mathrm{CFU} \mathrm{ml}{ }^{-1}$ after $4 \mathrm{~d}$. During the rapid growth phase, the main mulberry juice sugars, glucose and fructose, were largely consumed, and the acidic metabolites, lactic acid and acetic acid, were produced accordingly. A slow decrease in the concentration of the main organic acid, citric acid, was also observed during fermentation. After $4 \mathrm{~d}$ fermentation, anthocyanin content showed a $44.4 \%$ reduction, but the total amount of soluble phenolics and $\alpha$-glucosidase inhibitory activity showed no significant changes $(\mathrm{P}>0.05)$. This suggests that $L$. mesenteroides fermentation of mulberry juice is a good strategy to enhance its probiotic value and to decrease the sugar content without changing the anti-glucosidase activity, which is required to reduce postprandial rise in blood glucose.
\end{abstract}

Keywords: mulberry juice, fermentation, anti-glucosidase, Leuconostoc mesenteroides

Type 2 diabetes has reached worldwide epidemic proportions due to changes in people's lifestyle and dietary habits. Alfa-glucosidase inhibitors are usually used to prevent or medically treat type 2 diabetes. These inhibitors combine with intestine $\alpha$-glucosidase and block the uptake of postprandial blood glucose (DAAR et al., 2007; ANKOLEKAR et al., 2012). Although powerful synthetic $\alpha$-glucosidase inhibitors (e.g., Voglibose) are available, they can cause hepatic disorders and other negative gastrointestinal symptoms (Holman, 1998). Hence, natural $\alpha$-glucosidase inhibitors from food sources have become attractive therapeutic approach for treating postprandial hyperglycemia (Murai et al., 2002; DE Melo et al., 2006).

Mulberry, Morus genus, is a deciduous tree native to warm and subtropical regions of Asia, Africa, North America, and southern Europe (Perez-Gregorio et al., 2011). In most mulberry-growing countries, particularly China, mulberry was grown for its foliage to feed the silkworm (Bombyx mori). At present, many mulberry-growing areas in China have focused on enhancing fruit production, and some new fruit Morus species have been bred. Consumer acceptance of mulberry fruit has been positive because of its high content of anthocyanins and naturally occurring $\alpha$-glucosidase inhibitors (Du et al., 2008). The rate of consumption could be increased even further by developing health-promoting products, such as those containing probiotics produced by fermentation. Probiotics represent probably the

\footnotetext{
* To whom correspondence should be addressed.

Phone: +86-15975596649; fax: +86-(20)872-37273; e-mail: 499072725@qq.com
} 
archetypal functional ingredient, and are defined as a living microbial supplement, which beneficially affect the host by improving its intestinal microbial balance. Probiotics have been added to yogurt and other fermented dairy products (SAAD et al., 2013). However, the demand for non-dairy probiotic products has increased because of the problems associated with the high cholesterol content, allergy risks, and other negative factors associated with the consumption of dairy products. These concerns have led to the development of probiotic products from various food matrices including fruits and vegetables (MousAvi et al. 2011; ANKOLEKAR et al., 2012). Leuconostoc mesenteroides is a potential probiotic lactic acid bacterium, which has been detected in raw milk cheeses (NiETO-ARribas et al., 2010; SAAD et al., 2013). Moreover, there are several studies that report the presence of Leuconostoc in cheese during ripening and the using of Leuconostoc strains in Manchego cheese manufacture (Nieto-Arribas et al., 2010; SAAD et al., 2013).

In this study, mulberry juice was fermented using probiotic L. mesenteroides and changes of microbial population, sugar, organic acids, anthocyanins, total soluble phenolics contents, and anti-glucosidase activity were investigated. A further aim was to determine the suitability of mulberry juice as a raw material for the production of non-dairy probiotic drink.

\section{Materials and methods}

\subsection{Leuconostoc mesenteroides cultures}

A single L. mesenteroides strain was isolated from litchi fruit and activated to stationary phase in MRS broth (Guangzhou HuanKai Microbiological Technology Co. Ltd., Guangdong, China) before inoculating mulberry juice.

\subsection{Fermentation of mulberry juice}

The fruits of Morus atropurpurea (Roxb.) at a full ripe stage purchased from a local market were processed for 3-4 min in a pulper (Midea brand, Guangdong, China), and then passed through filter cloth $(100 \mathrm{mesh})$. After pasteurization for $1 \mathrm{~min}$ at $95^{\circ} \mathrm{C}$ and cooling to $30^{\circ} \mathrm{C}$, the juice $(500 \mathrm{ml})$ was inoculated with $L$. mesenteroides to yield an initial concentration of $5.0 \log \mathrm{CFU} \mathrm{ml}{ }^{-1}$. Samples of juice incubated at $30^{\circ} \mathrm{C}$ were taken at regular intervals, and part of the sample was tenfold serially diluted with $0.85 \%(\mathrm{w} / \mathrm{v}) \mathrm{NaCl}$ solution for microbial analysis on MRS agar plates incubated at $30^{\circ} \mathrm{C}$ for $2 \mathrm{~d}$. The rest of the sample was centrifuged at $8000 \mathrm{~g}$ for $5 \mathrm{~min}$ at $4{ }^{\circ} \mathrm{C}$ and the supernatant was recovered for further assays.

\subsection{Sugars, organic acids, and anthocyanins determination}

Sugars, organic acids, and anthocyanins were analyzed by HPLC in an Agilent system. The volume of the injected sample for each run was $20 \mu$, while quantification was performed by external calibration based on peak area. Sugars were quantified by a RI detector and separated on a Shodex Asahipak $\mathrm{NH}_{2} \mathrm{P}-504 \mathrm{E}(250 \times 4.6 \mathrm{~mm})$ column using 75\% acetonitrile aqueous solution as the mobile phase at a flow rate $1 \mathrm{ml} \mathrm{min}^{-1}$ and $30{ }^{\circ} \mathrm{C}$. Organic acids were separated on an Agilent ZORBAX SB-C18 $(4.6 \times 250 \mathrm{~mm})$ column at $30{ }^{\circ} \mathrm{C}$ using $0.02 \mathrm{~mol} \mathrm{l}^{-1}$ $\left(\mathrm{NH}_{4}\right)_{2} \mathrm{HPO}_{4}$ aqueous solution ( $\mathrm{pH} 2.7$ ) as the elution at a flow rate $0.8 \mathrm{ml} \mathrm{min} \mathrm{m}^{-1}$, and quantified with a UV-VIS detector at $210 \mathrm{~nm}$. Separations of anthocyanins were performed on a Waters $\mathrm{XBridge}^{\mathrm{TM}} \mathrm{C} 18(4.6 \times 250 \mathrm{~mm})$ column by gradient elution with solvent $\mathrm{A}$ (formic acid:water, 10:90, v/v) and solvent B (acetonitrile) at $1 \mathrm{ml} \mathrm{min}^{-1}$, and quantified at $520 \mathrm{~nm}$ by a UV-VIS 
detector. The gradient steps were as follows: $0-7 \mathrm{~min}, 6 \%-9 \% \mathrm{~B}$ in $\mathrm{A} ; 7-18 \mathrm{~min}, 9 \%-11 \% \mathrm{~B}$ in $\mathrm{A}$; $18-30 \mathrm{~min}, 11 \%-30 \% \mathrm{~B}$ in $\mathrm{A} ; 30-34 \mathrm{~min}, 30 \% \mathrm{~B}$ in $\mathrm{A} ; 34-35 \mathrm{~min}, 30-15 \% \mathrm{~B}$ in $\mathrm{A}$; and $35-40 \min 15 \% \mathrm{~B}$.

\subsection{Determination of $\mathrm{pH}$ and total soluble phenolics content}

The $\mathrm{pH}$ of the fermented mulberry juice $\left(20 \pm 1{ }^{\circ} \mathrm{C}\right)$ was measured using a Metrohm $744 \mathrm{pH}$ meter with a glass electrode (Metrohm Co. Ltd., Switzerland). Total soluble phenolics content of the fermented mulberry juice were determined using the Folin-Ciocalteu method (SAURACALIXTo, 1998) and expressed as gallic acid equivalent (GAE) $\mathrm{g}^{-1}$ of juice.

\subsection{Assay of $\alpha$-glucosidase inhibitory activity}

The $\alpha$-glucosidase inhibitory activity was determined as described by ANKOLEKAR and coworkers. (2012). Each sample of the fermented mulberry juice $(20 \mu 1)$ was diluted 15 times with $0.1 \mathrm{~mol}^{-1}$ sodium phosphate buffer (pH 6.9) before adding to the well of 96-well plates. The $\alpha$-glucosidase inhibitory activity was expressed as percentage inhibition.

\subsection{Statistical analysis}

The fermentation of mulberry juice was repeated three times and the results were expressed as average \pm standard deviation. Analysis of variance and paired $t$ tests were accomplished with SPSS Statistics 19.0 (IBM Co., New York, USA). Duncan's multiple range tests were used to determine statistically significant differences of variables at $95 \%$ confidence.

\section{Results and discussion}

\subsection{Growth of L. mesenteroides and substrate consumption}

As presented in Fig. 1, a slight increase in L. mesenteroides counts in mulberry juice was observed during the first day of fermentation, followed by a rapid growth and reaching nearly $8.6 \log \mathrm{CFU} \mathrm{m} \mathrm{m}^{-1}$ after $4 \mathrm{~d}$ of fermentation at $30^{\circ} \mathrm{C}$. The growth of L. mesenteroides was slower in mulberry juice as compared with cheese or cabbage matrices, which indicated that some substances (e.g., phenolics) in mulberry juice might inhibit L. mesenteroides growth (Breidt et al., 1995; Rodriguez et al., 2009; Nieto-Arribas et al., 2010).

HPLC analysis of sugar and organic acids (Figs 2 and 3) showed that glucose and fructose were the dominant sugars, while citric acid was the dominant organic acid in mulberry juice. About $69.1 \%$ of fructose and $79.5 \%$ of glucose were utilized after $4 \mathrm{~d}$ of fermentation (Fig. 2), whereas citric acid slowly decreased during the rapid growth phase (Fig. 3). Previous studies have reported that lactic acid bacteria can utilize citric acid as a carbon and energy source (Mousavi et al., 2011). After 4 d, L. mesenteroides counts started to decline, and no significant further reductions $(\mathrm{P}>0.05)$ in glucose, fructose, and citric acid (Figs 2 and 3) were observed. After $3 \mathrm{~d}$ fermentation, the $\mathrm{pH}$ values of the mulberry juice dropped to 3.7 from an initial $\mathrm{pH}$ of 4.05 (Fig. 2) reflecting the production of acidic metabolites. Lactic acid and acetic acid are recognized as the main metabolite produced by L. mesenteroides (BREIDT et al., 1995). A major increase in lactic acid and acetic acid concentrations was observed during the exponential phase of $L$. mesenteroides growth, and after $4 \mathrm{~d}$ reaching $6.99 \mathrm{~g}$ acetic acid $\mathrm{l}^{-1}$ and $4.78 \mathrm{~g}$ lactic acid $\mathrm{l}^{-1}$ (Fig. 3). 


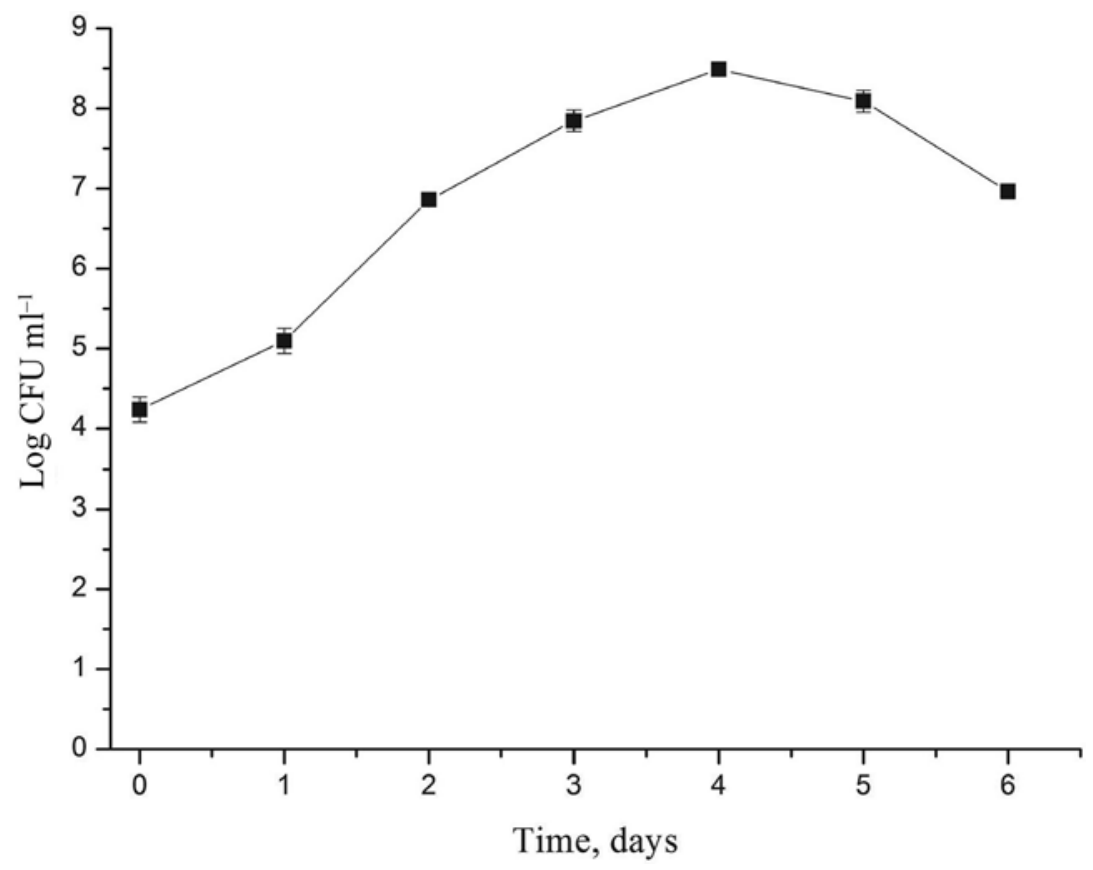

Fig. 1. Growth of L. mesenteroides in mulberry juice at $30^{\circ} \mathrm{C}$

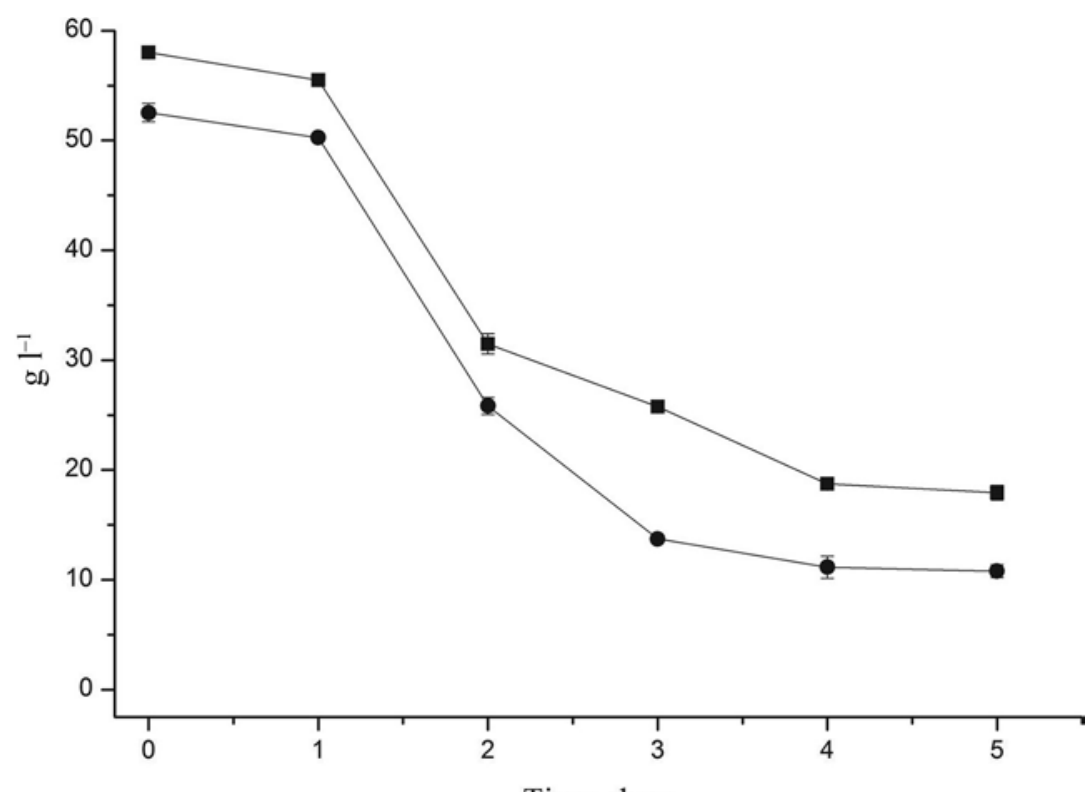

Time, days

Fig. 2. Sugar utilization during fermentation of mulberry juice at $30{ }^{\circ} \mathrm{C}$ with L. mesenteroides. ఐ: Fructose; $\bullet$ glucose 


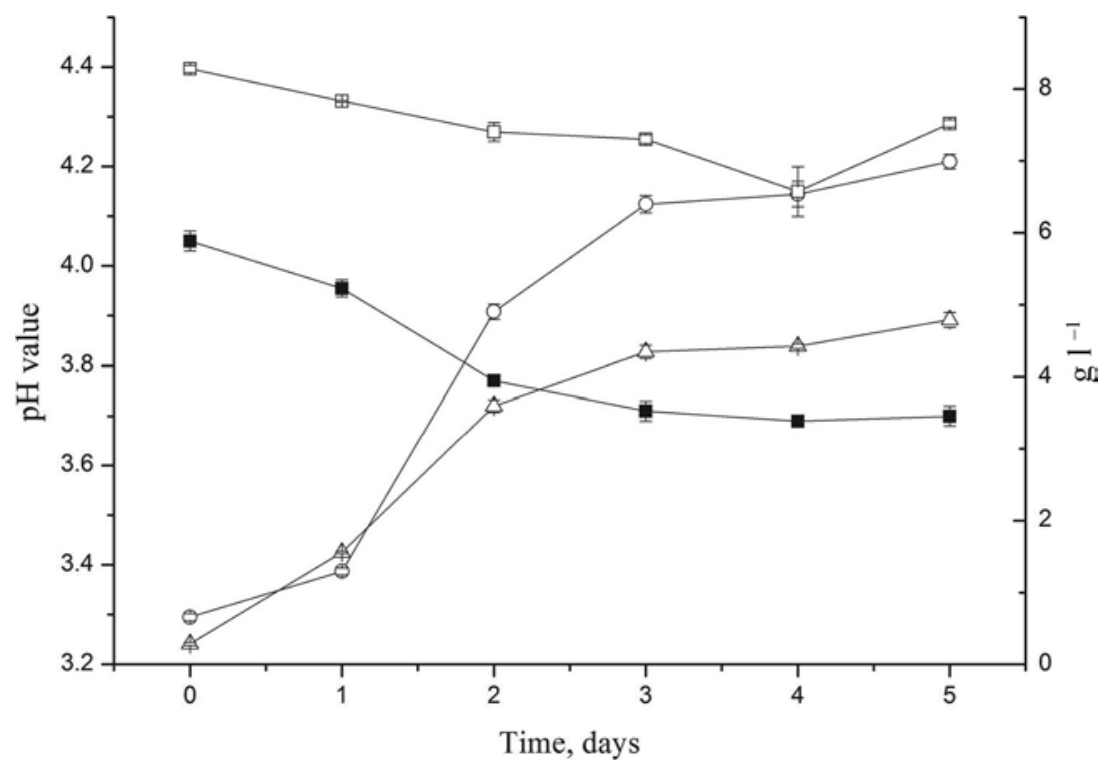

Fig. 3. Changes in the $\mathrm{pH}$ and the organic acids content during fermentation of mulberry juice at $30{ }^{\circ} \mathrm{C}$ by L. mesenteroides. $\mathbf{\square}$ : $\mathrm{pH} ; \triangle$ : lactic acid; O: acetic acid; $\square$ : citric acid

\subsection{Changes of anthocyanin and total soluble phenolics contents during fermentation}

Table 1 summarizes changes in the amounts of anthocyanins and total soluble phenolics during the fermentation of mulberry juice with $L$. mesenteroides. The main anthocyanins in mulberry fruit were cyanidin 3-O- $\beta$-D-glucopyranoside $(\mathrm{C} 3 \mathrm{G})$ and cyanidin $3-O-(6 "-O-\alpha-$ rhamnopyranosyl- $\beta$-D-glucopyranoside) (C3RG), which had been also detected in previous reports (LiU et al., 2004). In this study, the initial content of $\mathrm{C} 3 \mathrm{G}$ and $\mathrm{C} 3 \mathrm{RG}$ in mulberry juice was 0.599 and $0.518 \mathrm{~g} \mathrm{l}^{-1}$, respectively. No significant decrease $(\mathrm{P}>0.05)$ in $\mathrm{C} 3 \mathrm{G}$ and $\mathrm{C} 3 \mathrm{RG}$ contents was observed during the initial $1 \mathrm{~d}$ of fermentation (lag phase of L. mesenteroides), but a significant reduction $(\mathrm{P}<0.05)$ of $\mathrm{C} 3 \mathrm{G}$ and $\mathrm{C} 3 \mathrm{RG}$ was detected during the next $1-2 \mathrm{~d}$ of fermentation, decreasing to $28.1 \%$ and $35.8 \%$, respectively (Table 1), and stabilizing thereafter (Table 1). The negative impact of L. mesenteroides culture on the anthocyanin contents may reflect the production of hydrogen peroxide by L. mesenteroides. Several authors have shown that lactic acid bacteria culture can reduce dissolved oxygen in juices to $\mathrm{H}_{2} \mathrm{O}_{2}$ or water (CARIDI, 2002; SCIBISZ et al., 2012). The presence of hydrogen peroxide in a liquid sample could accelerate degradation of anthocyanin compounds and lead to the formation of brown polymers (RUENROENGKLIN et al., 2009). It was essential to detect the presence of hydrogen peroxide during fermentation of mulberry juice by L. mesenteroides in ongoing follow-up studies. 
Table 1. Changes of anthocyanins and total soluble phenolics (TSP) contents and $\alpha$-glucosidase inhibitory activity during fermentation of mulberry juice at $30^{\circ} \mathrm{C}$ by L. mesenteroides

\begin{tabular}{|c|c|c|c|c|}
\hline \multirow{2}{*}{$\begin{array}{l}\text { Fermentation } \\
\text { time (days) }\end{array}$} & \multicolumn{2}{|c|}{ Anthocyanin $\left(\mathrm{g} \mathrm{l}^{-1}\right)$} & \multirow{2}{*}{$\begin{array}{c}\text { TSP } \\
\left(\mathrm{GAE} \mathrm{g} \mathrm{l}^{-1}\right)\end{array}$} & \multirow{2}{*}{$\begin{array}{l}\alpha \text {-glucosidase } \\
(\% \text { inhibition })\end{array}$} \\
\hline & $\mathrm{C} 3 \mathrm{G}$ & $\mathrm{C} 3 \mathrm{RG}$ & & \\
\hline 0 & $0.599 \pm 0.021^{\mathrm{a}}$ & $0.518 \pm 0.018^{\mathrm{a}}$ & $2.99 \pm 0.05^{\mathrm{a}}$ & $74.5 \pm 2.8^{\mathrm{a}}$ \\
\hline 1 & $0.549 \pm 0.023^{\mathrm{a}}$ & $0.472 \pm 0.023^{\mathrm{a}}$ & $2.50 \pm 0.06^{\mathrm{c}}$ & $77.9 \pm 2.49^{\mathrm{a}}$ \\
\hline 2 & $0.395 \pm 0.023^{\mathrm{b}}$ & $0.303 \pm 0.031^{\mathrm{b}}$ & $2.94 \pm 0.11^{\mathrm{a}}$ & $78.4 \pm 1.8^{\mathrm{a}}$ \\
\hline 3 & $0.387 \pm 0.031^{\mathrm{b}}$ & $0.296 \pm 0.029^{b}$ & $2.63 \pm 0.07^{\mathrm{c}}$ & $78.0 \pm 1.6^{\mathrm{a}}$ \\
\hline 4 & $0.353 \pm 0.028^{\mathrm{b}}$ & $0.278 \pm 0.031^{\mathrm{b}}$ & $2.70 \pm 0.05^{\mathrm{bc}}$ & $74.2 \pm 3.1^{\mathrm{a}}$ \\
\hline 5 & $0.361 \pm 0.031^{b}$ & $0.294 \pm 0.033^{b}$ & $2.88 \pm 0.03^{\mathrm{ab}}$ & $76.7 \pm 2.4^{\mathrm{a}}$ \\
\hline
\end{tabular}

Values with different superscripts are different at $\mathrm{P}<0.05$

A slight fluctuation in total soluble phenolics during mulberry juice fermentation was

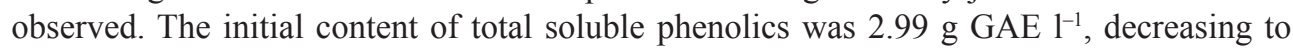
$2.88 \mathrm{~g} \mathrm{GAE}^{-1}$ after $5 \mathrm{~d}$ (Table 1). Phenolics in mulberry fruit occur mainly as anthocyanins, glycosyl derivatives of quercetin, hydroxycinnamic acid, and ellagic acid derivatives (PEREzGregorio et al., 2011). The change of total soluble phenolics composition in fermented mulberry juice may reflect the formation and degradation of polymeric phenolics and the degradation of small phenolics (McCue and Shetty, 2005; Rodriguez et al. 2009).

\subsection{Changes in $\alpha$-glucosidase inhibitory activity during fermentation}

The measurements of $\alpha$-glucosidase inhibitory activity of mulberry juice indicates that mulberry juice has the potential to inhibit this key intestinal enzyme associated with the postprandial rise in blood glucose. No significant change $(\mathrm{P}>0.05)$ was observed in the $\alpha$-glucosidase inhibitory activity of mulberry juice during fermentation (Table 1). Although the content of phenolics during fermentation of mulberries juice showed a slight fluctuation, the $\alpha$-glucosidase inhibitory activity of mulberry juice was rather stable during fermentation. It was reported that the $\alpha$-glucosidase inhibitory activity of phenolics is affected by their chemical structure (DE MELO et al., 2006). The formation/degradation of large polymeric phenolics and the degradation of small phenolics during fermentation may increase or decrease the $\alpha$-glucosidase inhibitory activity (YANG et al., 2012; You et al., 2012; PHAN et al., 2013). In addition, some studies reported that the production of acidic metabolites by lactic bacteria may further enhance the $\alpha$-glucosidase inhibitory activity (ApOsTOLIDIs et al., 2007; ANKoleKar et al., 2012).

\section{Conclusions}

Leuconostoc mesenteroides can grow rapidly in mulberry juice, reaching a maximum of nearly $8.6 \log \mathrm{CFU} \mathrm{m} \mathrm{m}^{-1}$ after $4 \mathrm{~d}$ at $30{ }^{\circ} \mathrm{C}$. During the rapid growth of $L$. mesenteroides, glucose and fructose were largely consumed, leading to the production of lactic acid and 
acetic acid. A slow decrease of citric acid was also observed during fermentation. After $4 \mathrm{~d}$ fermentation, the anthocyanin content showed a $44.4 \%$ reduction, but the amounts of total soluble phenolics and $\alpha$-glucosidase inhibitory activity showed no significant change $(\mathrm{P}>0.05)$. These results show that L. mesenteroides fermentation of mulberry juice is a promising strategy to enhance its probiotic value and decrease the content of sugar without affecting its ability to reduce the postprandial rise in blood glucose.

This research was supported by Project No. 201303073-05 of Public sector (Agriculture) research of China, and Project No. 2012B010300028 of Guangdong Science and Technology Plan, China.

\section{References}

Ankolekar, C., Pinto, M., Greene, D. \& Shetty, K. (2012): In vitro bioassay based screening of antihyperglycemia and antihypertensive activities of Lactobacillus acidophilus fermented pear juice. Innov. Fd Sci. Emerg Technol., 13, 221-230.

Apostolidis, E., Kwon, Y.I., Ghaedian, R. \& Shetty, K. (2007): Fermentation of milk and soymilk by Lactobacillus bulgaricus and Lactobacillus acidophilus enhances functionality for potential dietary management of hyperglycemia and hypertension. Fd Biotechnol., 21, 217-236.

Breidt, F., Crowley, K.A. \& Fleming, H.P. (1995): Controlling cabbage fermentations with nisin and nisin-resistant Leuconostoc mesenteroides. Fd Microbiol., 12, 109-116.

CARIDI, A. (2002): Selection of Escherichia coli-inhibiting strains of Lactobacillus paracasei subsp. paracasei. J. Ind. Microbiol. Biot., 29, 303-308.

Daar, A.S., Singer, P.A., Persad, D.L., Pramming, S.K., Matthews, D.R., Beaglehole, R., Bernstein, A., Borysiewicz, L.K., Colagiuri, S., Ganguly, N., Glass, R.I., Finegood, D.T., Koplan, J., Nabel, E.G., Sarna, G., Sarrafzadegan, N., Smith, R., Yach, D. \& Bell, J. (2007): Grand challenges in chronic non-communicable diseases. Nature, 450, 494-496.

DE Melo, E.B, Gomes, A.S. \& CARvalho, I. (2006): $\alpha$ - and $\beta$-Glucosidase inhibitors: chemical structure and biological activity. Tetrahedron, 62, 10277-10302.

Du, Q., ZHENG, J. \& Xu, Y. (2008): Composition of anthocyanins in mulberry and their antioxidant activity. $J . F d$ Compos. Anal., 21, 390-395.

Holman, R.R. (1998): Assessing the potential for $\alpha$-glucosidase inhibitors in prediabetic states. Diabetes Res. Clin. Pr., 40 Suppl., 21-25.

Liu, X., XiaO, G., Chen, W., Xu Y. \& Wu, J. (2004): Quantification and purification of mulberry anthocyanins with macroporous resins. J. Biomed. Biotechnol., 5, 326-331.

McCue, P.P. \& SheTty, K. (2005): Phenolic antioxidant mobilization during yogurt production from soymilk using kefir cultures. Process Biochem., 40, 1791-1797.

Mousavi, Z.E., Mousavi, S.M., Razavi, S.H., Emam-Dıomeh. Z. \& Kiani. H. (2011): Fermentation of pomegranate juice by probiotic lactic acid bacteria. World J. Microb. Biot., 27, 123-128.

Murai, A., Imamura, K., Takada, M., Ogawa, K., Usui, T. \& Okumura, J. (2002): Control of postprandial hyperglycaemia by galactosyl maltobionolactone and its novel anti-amylase effect in mice. Life Sci., 71, $1405-1415$.

Nieto-Arribas, P., Sesena, S., Poveda, J.M., Palop, L. \& Cabezas, L. (2010): Genotypic and technological characterization of Leuconostoc isolates to be used as adjunct starters in Manchego cheese manufacture. $F d$ Microbiol., 27, 85-93.

Perez-Gregorio, M.R., Regueiro, J., Alonso-Gonzalez, E., Pastrana-Castro, L.M. \& Simal-Gandara, J. (2011): Influence of alcoholic fermentation process on antioxidant activity and phenolic levels from mulberries (Morus nigra L.). LWT-Food Sci. Technol., 44, 1793-1801.

Phan, M.A.T., Wang, J., Tang, J., LeE, Y.Z. \& NG, K. (2013): Evaluation of $\alpha$-glucosidase inhibition potential of some flavonoids from Epimedium brevicornum. LWT-Food Sci. Technol., 53, 492-498.

Rodriguez, H., Curiel, J.A., Landete J.M., Delasrivas, B., Lopezdefelipe, F., Gomez-Cordoves, C., Mancheno, J.M. \& Munoz, R. (2009): Food phenolics and lactic acid bacteria. Int. J. Fd Microbiol., 132, 79-90. 
Ruenroengklin, N., Yang, B., Lin, H., Chen, F. \& Jiang, Y. (2009): Degradation of anthocyanin from litchi fruit pericarp by $\mathrm{H}_{2} \mathrm{O}_{2}$ and hydroxyl radical. Fd Chem., 116, 995-998.

SaAd, N., Delattre, C., Urdaci, M., Schmitter, J.M. \& Bressollier, P. (2013): An overview of the last advances in probiotic and prebiotic field. LWT-Food Sci. Technol., 50, 1-16.

Saura-CaliXto, F. (1998): Antioxidant dietary fiber product: a new concept and a potential food ingredient. J. Agric. Fd Chem., 46, 4303-4306.

Scibisz, I., Ziarno, M., Mitek, M. \& ZaręBA, D. (2012): Effect of probiotic cultures on the stability of anthocyanins in blueberry yoghurts. LWT-Food Sci. Technol. 49, 208-212.

YANG, Z., WANG, Y., WANG, Y. \& Zhang, Y. (2012): Bioassay-guided screening and isolation of $\alpha$-glucosidase and tyrosinase inhibitors from leaves of Morus alba. Fd Chem., 131, 617-625.

You, Q., Chen, F., Wang, X., JiAnG, Y. \& Lin, S. (2012): Anti-diabetic activities of phenolic compounds in muscadine against alpha-glucosidase and pancreatic lipase. LWT-Food Sci. Technol., 46, 164-168. 